\title{
Expression of Transketolase like gene 1 (TKTL1) predicts disease-free survival in patients with locally advanced rectal cancer receiving neoadjuvant chemoradiotherapy
}

Juliana Schwaab ${ }^{1 \dagger}$, Karoline Horisberger ${ }^{2 \dagger}$, Philipp Ströbel ${ }^{3}$, Beatrice Bohn ${ }^{1}$, Deniz Gencer ${ }^{1}$, Georg Kähler ${ }^{2}$, Peter Kienle ${ }^{2}$, Stefan Post ${ }^{2}$, Frederik Wenz ${ }^{4}$, Wolf-Karsten Hofmann ${ }^{1}$, Ralf-Dieter Hofheinz ${ }^{1}$ and Philipp Erben ${ }^{1 *}$

\begin{abstract}
Background: For patients with locally advanced rectal cancer (LARC) neoadjuvant chemoradiotherapy is recommended as standard therapy. So far, no predictive or prognostic molecular factors for patients undergoing multimodal treatment are established. Increased angiogenesis and altered tumour metabolism as adaption to hypoxic conditions in cancers play an important role in tumour progression and metastasis. Enhanced expression of Vascular-endothelial-growth-factor-receptor (VEGF-R) and Transketolase-like-1 (TKTL1) are related to hypoxic conditions in tumours. In search for potential prognostic molecular markers we investigated the expression of VEGFR-1, VEGFR-2 and TKTL1 in patients with LARC treated with neoadjuvant chemoradiotherapy and cetuximab.

Methods: Tumour and corresponding normal tissue from pre-therapeutic biopsies of 33 patients (m: 23, f: 10; median age: 61 years) with LARC treated in phase-I and II trials with neoadjuvant chemoradiotherapy (cetuximab, irinotecan, capecitabine in combination with radiotherapy) were analysed by quantitative PCR.

Results: Significantly higher expression of VEGFR-1/2 was found in tumour tissue in pre-treatment biopsies as well as in resected specimen after neoadjuvant chemoradiotherapy compared to corresponding normal tissue. High TKTL 1 expression significantly correlated with disease free survival. None of the markers had influence on early response parameters such as tumour regression grading. There was no correlation of gene expression between the investigated markers.

Conclusion: High TKTL-1 expression correlates with poor prognosis in terms of 3 year disease-free survival in patients with LARC treated with intensified neoadjuvant chemoradiotherapy and may therefore serve as a molecular prognostic marker which should be further evaluated in randomised clinical trials.
\end{abstract}

Keywords: hypoxia, radiochemotherapy, rectal cancer, TKTL1, VEGFR-1/2

\section{Background}

Neoadjuvant chemoradiotherapy has become standard treatment for locally advanced rectal cancer due to improved local tumour control. Distant metastases are currently the predominant cause for treatment failure [1]. Therefore, the search for prognostic and predictive

\footnotetext{
* Correspondence: philipp.erben@medma.uni-heidelberg.de

+ Contributed equally

'III. Medizinische Klinik, Universitätsmedizin Mannheim, Theodor-Kutzer-Ufer 1-3, 68167 Mannheim, Germany

Full list of author information is available at the end of the article
}

markers has been widely promoted in the last few years $[2,3]$. To date, no validated prognostic or predictive molecular marker in the setting of locally advanced rectal cancer has been established.

Angiogenesis as a central process in progression of solid tumours is a well-established aspect of cancer biology [4]. Inhibition of involved tyrosine kinase receptors such as the epidermal growth factor (EGFR) and the vascular endothelial growth factor receptor (VEGFR) or its ligand VEGF is effective in several tumour types $[5,6]$. VEGFR-2 is believed to be the major mediator of

\section{Biomed Central}


angiogenesis in human tumours, whereas VEGFR-1 is said to play its primary role during embryogenesis and regulates apoptosis and tumour growth in malignancies [7]. Several studies have outlined a trend towards more aggressive tumour growth in terms of distant metastasis in patients with VEGF-overexpressing rectal cancer undergoing neoadjuvant treatment [8]. However, expression data of the different VEGF subtypes and their receptors in colorectal cancer still remain controversial [9-11] and their prognostic impact on patients treated with neoadjuvant cetuximab-based chemoradiotherapy has not yet been evaluated.

Many cancers show a strongly enhanced glycolytic metabolism of carbohydrates even in the presence of oxygen ("aerobic glycolysis"), a phenomenon firstly described by Nobel laureate Otto Warburg ("Warburg effect") [12]. The detection of the Transketolase-like-1 (TKTL1) protein and its role in the pentose phosphate pathway (PPP) first described a link between enhanced glycolysis and cancer [13]. Increased TKTL1 expression on mRNA and protein level correlates with poor patient outcome and metastasis in many solid tumours [14-18]. Specific inhibition of TKTL1 mRNA has been shown to inhibit cancer cell proliferation in functional studies $[14,17]$.

In the present study, we aimed to analyze the potential prognostic and predictive influence of VEGFR-1/2 and TKTL1 expression on early response parameters such as pathological tumour regression grading (TRG) and tumour downstaging and on 3-year disease-free survival in patients with LARC undergoing cetuximabbased chemoradiotherapy within clinical trials.

\section{Methods}

\section{Patients and Treatment}

The present analysis comprises patients with histologically confirmed, locally advanced non-metastatic rectal adenocarcinoma (endorectal ultrasound stage cT3-4, any $\mathrm{N}$ or cT2, $\mathrm{N}+$ distal rectum). All patients participated in clinical trials of intensified neoadjuvant chemoradiotherapy including weekly irinotecan $\left(40-50 \mathrm{mg} / \mathrm{m}^{2}\right)$ and cetuximab (initial dose of $400 \mathrm{mg} / \mathrm{m}^{2}$ then $250 \mathrm{mg} / \mathrm{m}^{2}$ ), and daily capecitabine $\left(400-500 \mathrm{mg} / \mathrm{m}^{2}\right.$ b.i.d.) in combination with pelvic radiotherapy $(45 \mathrm{~Gy}+5.4 \mathrm{~Gy})$ as previously described $[19,20]$. Follow up of patients was carried out according to the German study group for gastrointestinal Oncology [21]. Patient characteristics are listed in Table 1.

Patients provided written informed consent for the participation in the clinical study as well as for the investigation of biopsy material. The clinical study protocol was reviewed and approved by the local institutional
Table 1 Patient and tumour characteristics in 33 patients treated with cetuximab based chemoradiotherapy

\begin{tabular}{|c|c|c|}
\hline & Patients (n) & $\%$ \\
\hline Patients included & 33 & 100 \\
\hline Median age (range) & \multicolumn{2}{|c|}{$61(33-76)$} \\
\hline \multicolumn{3}{|l|}{ Gender } \\
\hline Male & 23 & 70 \\
\hline Female & 10 & 30 \\
\hline \multicolumn{3}{|l|}{ Performance Status (ECOG*) } \\
\hline 0 & 23 & 70 \\
\hline 1 & 9 & 27 \\
\hline 2 & 1 & 3 \\
\hline \multicolumn{3}{|l|}{ Tumour marker } \\
\hline CEA, median (range) & \multicolumn{2}{|c|}{$2,4 \mu \mathrm{g} / \mathrm{l}(0.5-50,3)$} \\
\hline CA 19-9, median (range) & \multicolumn{2}{|c|}{$10 \mathrm{kU} / \mathrm{l}(1-298)$} \\
\hline \multicolumn{3}{|l|}{ Clinical T-staging (TRUS ${ }^{\S \S}$ ) } \\
\hline сT2 & 6 & 18 \\
\hline cT3 & 24 & 73 \\
\hline cT4 & 3 & 9 \\
\hline \multicolumn{3}{|l|}{ Clinical N-staging (TRUS ${ }^{\S \S}$ ) } \\
\hline $\mathrm{cN}$ negative & 10 & 30,3 \\
\hline $\mathrm{cN}$ positive & 23 & 69,7 \\
\hline \multicolumn{3}{|l|}{$\mathrm{TRG}^{\S}\left(\mathrm{JSCCR}{ }^{\mathrm{H}}\right)$} \\
\hline 0 & 1 & 3 \\
\hline $1 \mathrm{a}$ & 6 & 18 \\
\hline $1 b$ & 4 & 12 \\
\hline 2 & 19 & 58 \\
\hline 3 & 3 & 9 \\
\hline
\end{tabular}

§§: Transrectal ultrasound; §: Tumour regression grade; $\#$ = Japanese Society for Cancer of the Colon and Rectum.

review board and the study was performed according to the Declaration of Helsinki.

\section{Pathological assessment and definition of tumour response}

Surgery was performed $4-6$ weeks after the completion of chemoradiotherapy. The pathological routine workup was described earlier [22].

Two classification systems were applied to describe response to chemoradiotherapy. The grade of histopathological regression has first been described using the Japanese Society for Cancer of the Colon and Rectum (JSCCR) grading system [23]. Tumours were classified as good-responders when assigned to tumour regression grades 2 or 3 (TRG 2 or TRG 3), and as bad-responders at regression grades 0 or 1 (TRG 0 or TRG 1).

Moreover, the histopathological downstaging after completion of preoperative chemoradiotherapy was used as surrogate parameter of tumour response, as previously described by Valentini et al [24]. A T-level 
downstaging of at least one T-level was considered to be a sign of response.

\section{Tissue samples, Real-time quantitative polymerase chain reaction}

Tumour material was obtained during rectoscopy before the initiation of chemoradiotherapy and during surgery of the primary tumour. Tumour biopsies $(n=33)$ and matching healthy mucosa $(n=33)$ were stored in RNAlater (Quiagen, Hilden, Germany) in liquid nitrogen, and stored at $-80^{\circ} \mathrm{C}$ until further extraction. RNA extraction and cDNA synthesis was performed according to standard protocols [25]. Total RNA was extracted after homogenisation of 15-30 mg tissue with the Ultra Turrax Tube Drive (Ika, Staufen, Germany) using TRIzol ${ }^{\mathrm{TM}}$ reagent (Invitrogen, Karlsruhe, Germany) according to the manufacturer's instructions. RNA was reversely transcribed using random hexamer priming and MMLV reverse transcriptase (Invitrogen).

Expression analysis of VEGFR-1, VEGFR-2 and TKTL1 was performed using the LightCycler instrument 1.5 (Roche Diagnostics, Mannheim, Germany). For sequences of amplification primers and hybridisation probes used see additional file 1 . Each $20 \mu \mathrm{l}$ reaction mix contained $4 \mu \mathrm{l}$ LightCycler Faststart DNA Masterplus Hyb Probes Master Mix (Roche Diagnostics), $2 \mu \mathrm{l}$ cDNA template or plasmid dilution, $0.5 \mu \mathrm{M}$ forward primer and $0.5 \mu \mathrm{M}$ reverse primer, $0.25 \mu \mathrm{M}$ anchor probe and $0.25 \mu \mathrm{M}$ sensor probe (TIB Molbiol, Berlin, Germany). Cycler conditions were the following: $10 \mathrm{~min}$ denaturation at $95^{\circ} \mathrm{C}, 50$ cycles of $10 \mathrm{sec}$ at $60^{\circ} \mathrm{C}$ (annealing VEGFR-1, -2, and TKTL1) and $26 \mathrm{sec}$ at $72^{\circ} \mathrm{C}$ (elongation). A $5 \mathrm{log}$ series of plasmid dilutions was amplified within the PCR runs for quantification of VEGFR-1, -2 and TKTL1. The LightCycler software prepares standard curves using linear regression analysis of the plasmid dilutions and calculates copy numbers of the unknown sample [26]. Values below the lowest standard dilution for TKTL1 (4 copies) and VEFGR-1/2 (40 copies) were assigned as negative. Beta-Glucuronidase (GUS) mRNA was quantified as internal control as previously described [27].

\section{Cloning of Quantification standards}

Cloning and transformation of the PCR products of TKTL1, VEGFR-1 and VEGFR-2 amplified from cell lines (SW480, K562 obtained from DSMZ, Braunschweig, Germany) was performed according to the manufacturer's instructions using the PCR2.1 TOPO vector (Invitrogen). Amplification reactions were undertaken for 32 cycles at $60^{\circ} \mathrm{C}$ annealing temperature. Cloning and transformation into Escherichia coli TOPO10F' was performed according to the manufacturer's instructions (Invitrogen). Plasmid DNA containing the desired construct was isolated using the Plasmid Mini Kit (Qiagen). Insertion sequences were confirmed by direct sequencing. The resulting plasmid was linearized by Not1 digestion (Roche Diagnostics). Dilutions of the linearized plasmid were prepared in $10 \mathrm{mM}$ Tris- $\mathrm{HCl}(\mathrm{pH}$ 8.0) and $1 \mathrm{mM}$ ethylenediaminetetraacetic acid containing $20 \mathrm{mg} / \mathrm{mL}$ tRNA (Roche Diagnostics).

ß-Glucuronidase (GUS) mRNA transcripts were measured as an internal control using a standard plasmid (pME-2) containing $B C R-A B L, A B L$, and GUS sequences [27]

In order to minimize dilution error of different plasmids containing target and housekeeping gene a common plasmid containing TKTL1 and GUS was constructed for further use using a previously published method [27].

\section{KRAS, PTEN and Survivin analysis}

$K R A S$ mutation analysis was performed for all samples by direct sequencing from DNA of microdissected tumor tissue samples as described [28]. PTEN status was determined by immunohistochemistry (IHC) using the PTEN antibody as described [28] (1:400, Cascade Bioscience, Winchester, MA, USA). All 33 patients were screened for PTEN mutations, 30 of which were evaluable. Three samples could not be taken into the analysis due to poor sample quality. Survivin expression analysis was performed on cDNA level of 30 patients from the studygroup using qPCR.

\section{Statistical analysis}

Differences in expression levels were compared using two-tailed Mann Whitney test. Differences in regression rates concerning the investigated tissue markers were evaluated by means of a two sided Fisher's Exact test. Disease-free survival was defined as the time between the start of chemoradiotherapy and tumour relapse (local failure and/or distant metastases) or death due to non-tumour related causes using the Kaplan-Meier method. Cut off level of median gene expression was used to divide low and high expressing groups. A pvalue of less than 0.05 was considered statistically significant.

\section{Results}

Patients, tumour characteristics and expression levels in tumour tissue

Patient and tumour characteristics are depicted in Table 1. Tumour tissue of a total of 33 patients $(n=23$ male, $\mathrm{n}=10$ female, median age 61, range 33 - 76) was analysed. TKTL1 expression was determined in 33 patients, while VEGRFR-2 expression was analysed in 32 and $V E G F R-1$ expression in 26 patients only due to scantness of tumour tissue. 
Normalised VEGFR-1/-2 expression of patients with LARC was significantly higher in pre-treatment tumour tissue in comparison to the corresponding normal mucosa (VEGFR-1; p $=0.0023$ and VEGFR-2; $\mathrm{p}=$ $0.0005)$ but failed to be statistically significant for TKTL1 ( $\mathrm{p}=0.082)$. Accordingly, after completion of chemoradiotherapy higher VEGFR-1/-2 expression levels $(\mathrm{p}=0.025 ; \mathrm{p}=0.063)$ were observed in tumour tissue as compared to healthy mucosa at time of surgery, whereas no differences in gene expression levels of VEGFR-1 and -2 were observed in tumour samples before and after neoadjuvant radiotherapy (Figure 1).

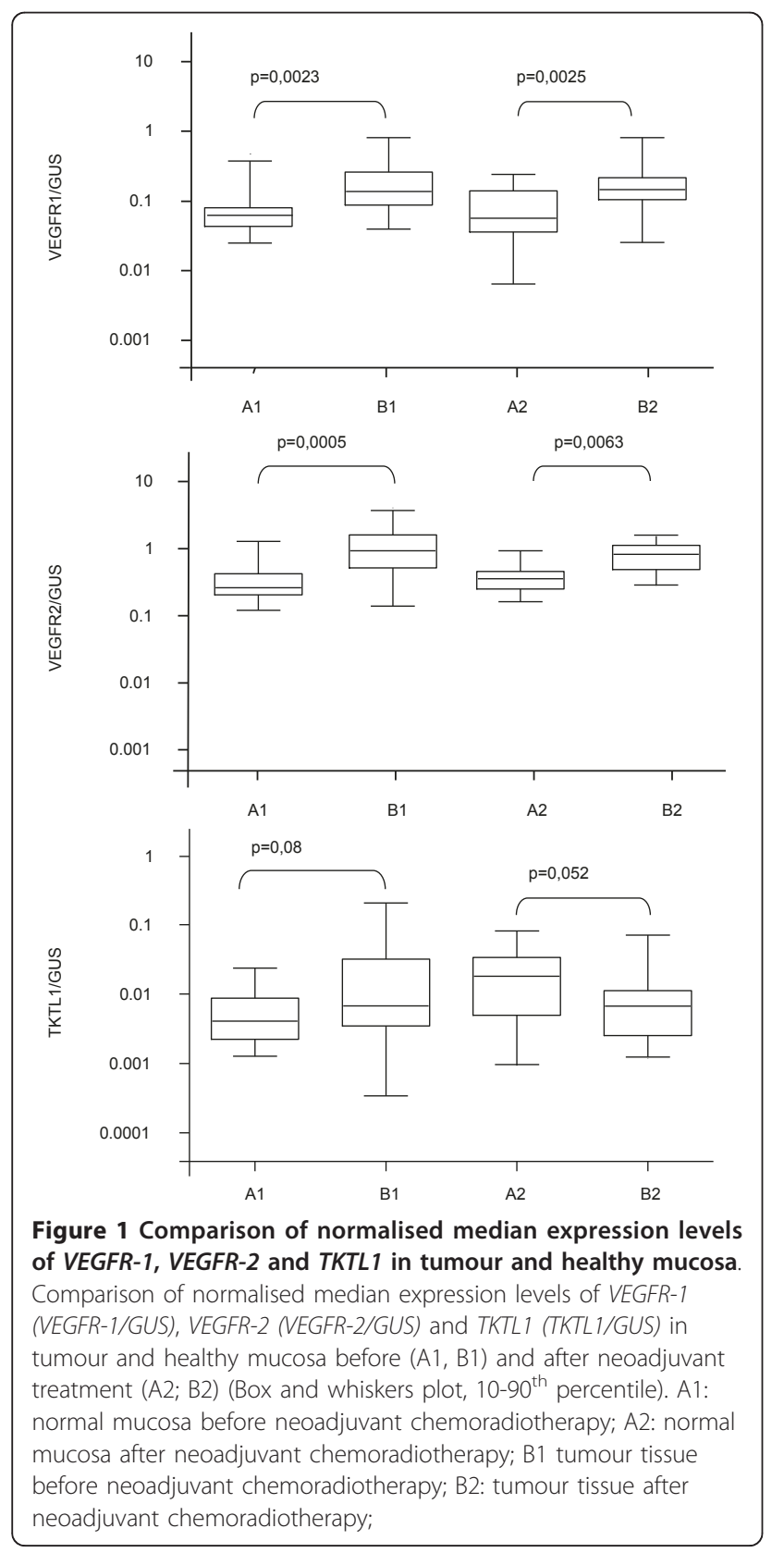

\section{Expression levels and pathological tumour response} (TRG, PCR)

A total of 11 out of 33 patients showed a poor response (33\%; defined as TRG of 0 or 1), while 22 patients had good response (67\%; TRG 2 or 3, Table 1). Pathological $\mathrm{T}$-downstaging was accomplished in 15 patients $(45 \%$, "T-responder"), 3 of whom (9\%) achieved a pathological complete remission (ypT0 N0). No significant correlation between the two scores could be seen in our cohort (CI: 0,7-2,1, p-value:0,4).

Median pre-treatment expression levels of the three genes were used as a cut off value, dividing patients into low and high-expression groups (Figure 1) No significant correlation was observed neither for the JSCCR grading (TRG) nor the complete pathological response (pCR) nor for gene expression levels (Table 2).

\section{Gene Expression levels and DFS}

All but one patient underwent curative surgery. The latter had an irresectable T4-tumour and revealed tumour progression with peritoneal spread during chemoradiotherapy. Median follow-up time was 33 months (range: 9-51). Local recurrence and distant metastases were recorded in two (12.5\%) and 10 patients (65\%), respectively.

A longer three-year DFS could be observed in patients with low TKTL1 expression (3-year DFS: 87\% versus $39 \%, \mathrm{n}=33, \mathrm{p}=0.01$, HR: 0.19, CI: 0,05-0,6), while three-year DFS was virtually identical for patients with high vs. low VEGFR-1 expression (3-year DFS: 69\% versus $68 \%, \mathrm{n}=26, \mathrm{p}=0,9$, HR: 1,04, CI: 0,26-4,2). The impact of VEGFR-2 expression on DFS failed statistical significance but a trend was observed regarding 3-year DFS in favour of patients with lower VEGFR-2 expression (3-year DFS: $81 \%$ versus $53 \%, \mathrm{n}=32, \mathrm{p}=0.19$, HR:0,43, CI: 0,13-2,15; see Figure 2).

Table 2 Prognostic value of pathological tumour response for VEGFR-1, VEGFR-2, and TKTL1

\begin{tabular}{|c|c|c|c|}
\hline & $\begin{array}{l}\text { VEGFR-1/GUS } \leq \\
\text { Median }(n=13)\end{array}$ & $\begin{array}{l}\text { VEGFR-1/GUS > } \\
\text { Median }(n=13)\end{array}$ & $\mathrm{p}$-value \\
\hline $\operatorname{TRG}^{+} 2-3$ & $9(69.2 \%)$ & $8(61.5 \%)$ & $p=1.0$ \\
\hline \multirow[t]{2}{*}{ pCR* (ypTo No) } & $2(15.4 \%)$ & $1(7.7 \%)$ & $p=1.0$ \\
\hline & $\begin{array}{l}\text { VEGFR-2/GUS } \leq \\
\text { Median }(n=16)\end{array}$ & $\begin{array}{l}\text { VEGFR-2/GUS > } \\
\text { Median }(n=16)\end{array}$ & \\
\hline $\operatorname{TRG}^{+} 2-3$ & $12(75 \%)$ & $9(56 \%)$ & $p=0.19$ \\
\hline \multirow[t]{2}{*}{ PCR* (ypT0 No) } & $2(16.7 \%)$ & $1(6.3 \%)$ & $p=1.0$ \\
\hline & $\begin{array}{c}\text { TKTL1/GUS } \leq \\
\text { Median }(n=17)\end{array}$ & $\begin{array}{c}\text { TKTL1/GUS > } \\
\text { Median }(n=16)\end{array}$ & \\
\hline TRG† $2-3$ & $11(64.5 \%)$ & $11(68.8 \%)$ & $p=1.0$ \\
\hline PCR* (ypT0 No) & $1(5.9 \%)$ & $2(12.5 \%)$ & $p=0.6$ \\
\hline
\end{tabular}




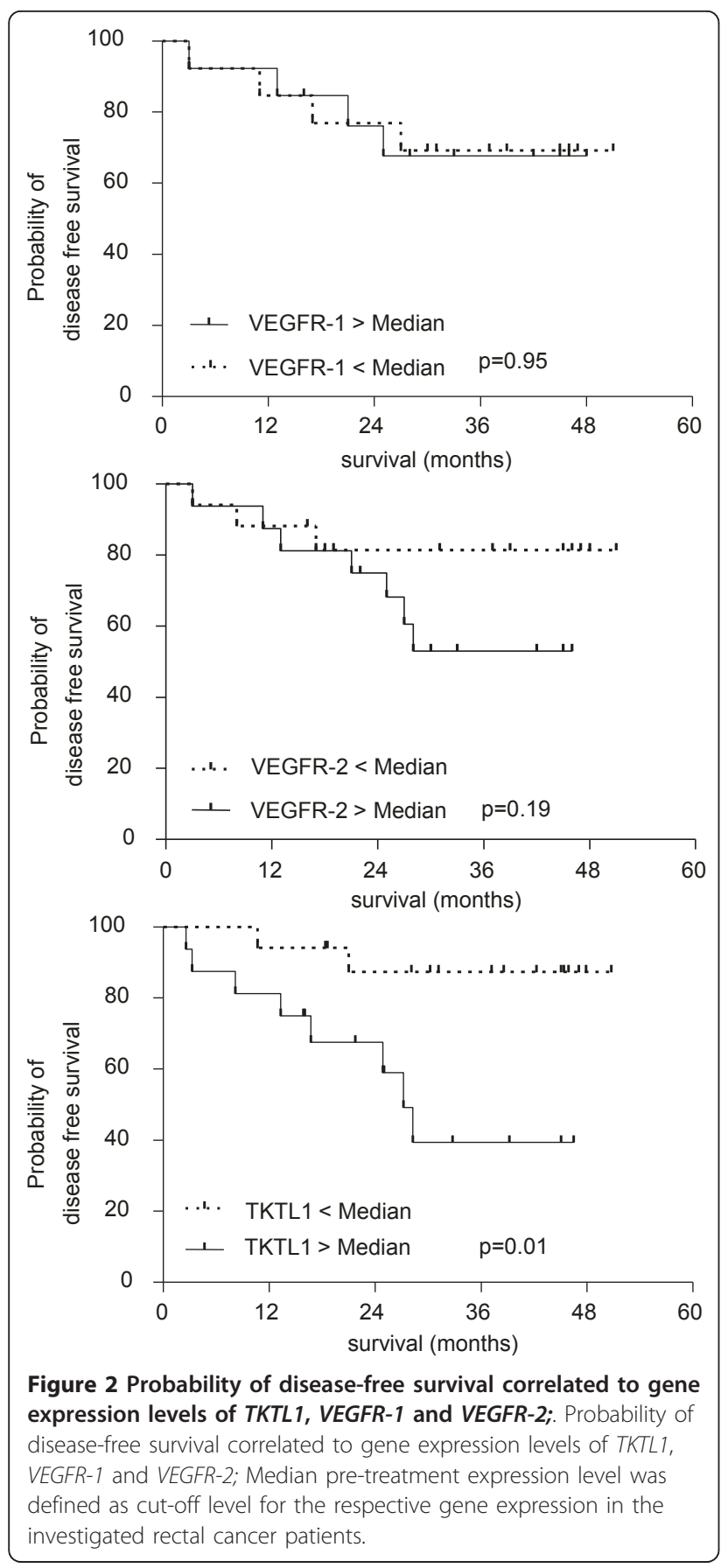

\section{Correlation of TKTL1 expression with clinical and molecular findings}

The high and low expressing patient groups are compared in Table 3 with respect to several clinical and molecular parameters. Median age in patients with a higher TKTL1 expression was younger compared to patients with low TKTL1 expression. No significant differences could be seen in initial tumour stage and TRG. Serum tumour markers in the patient group with higher
TKTL1 expression were slightly higher, but this did not reach statistical significance ( $\mathrm{p}$-value for CEA $\mathrm{p}=0.07$, $\mathrm{n}=16$, p-value for CA 19.9, $\mathrm{p}=0.18, \mathrm{n}=16$ ). Patients with high TKTL1 levels eventually developed metastases or local recurrence significantly more often than patients with low TKTL1 levels (11 vs. 1 pts., p = 0.0002). TKTL1 expression was correlated to VEGFR-1/ 2 and to PTEN, KRAS and Survivin expression in our cohort. Expression of the latter molecular markers has previously been published by our group $[28,29]$. No correlation between high TKTL1 expression and VEGFR-1 or -2 expression was demonstrated, while a tendency towards higher survivin expression in the TKTL1 overexpressing group could be detected (13 vs 17 pts., $\mathrm{p}=0.08)$.

\section{Discussion}

Despite intensive neoadjuvant treatment regimens using chemotherapy and radiotherapy, 35-40\% of patients with locally advanced rectal cancer (LARC) eventually will develop distant metastases and die of this disease. To date, no validated prognostic or predictive molecular marker in the setting of locally advanced rectal cancer is established to tailor treatment individually to the patients.

Angiogenesis is a central process in tumour progression, and enhanced glycolytic metabolism of carbohydrates even in the presence of oxygen ("aerobic glycolysis") has been demonstrated to be involved in progression and resistance in several solid tumours $[3,4,30,31]$. In the present study, we evaluated the potential prognostic and predictive impact of $V E G F R-1$, VEGFR-2 and TKTL1 mRNA expression levels in patients with LARC receiving intensified neoadjuvant chemoradiotherapy with capecitabine, irinotecan and cetuximab. Quantification of the examined genes was performed using qPCR and normalized against the housekeeping gene GUS.

The main finding of this study was an inferior 3-year DFS for patients with high TKTL1 expression as compared to those with low TKTL1 expression using qPCR (3 year DFS: $39 \%$ vs $87 \%$; $\mathrm{p}=0.017$ ). TKTL1, an altered isoform of the transketolase gene, is upregulated in many human cancers [14-17,32]. TKTL1 protein renders tumour cells autonomous by means of infinite glucose consumption irrespective of oxygen supply $[13,16]$. Transketolase reactions in the pentose phosphate pathway (PPP) convert glucose to ribose for nucleic acid synthesis and generate $\mathrm{NADPH}$, a reducing agent required for synthesis reactions in growing tumour cells. More than $85 \%$ of the nucleic acid in certain tumours derives from ribose generated in the nonoxidative part of the PPP [33]. 
Table 3 Clinical and laboratory findings dependent on TKTL1 expression status

\begin{tabular}{|c|c|c|c|}
\hline & $\begin{array}{c}\text { TKTL1/GUS } \leq \\
\text { Median }(n=17)\end{array}$ & $\begin{array}{c}\text { TKTL1/GUS > } \\
\text { Median }(n=16)\end{array}$ & $P$ value \\
\hline Median age $(n=33)$ : 61 years & 63 & 59 & $p=0.89$ \\
\hline \multirow[t]{2}{*}{ Clinical tumour stage } & uN negative $n=5(29 \%)$ & uN negative $n=5(31 \%)$ & $p=1.0$ \\
\hline & $\mathrm{uN}$ positive $\mathrm{n}=12(71 \%)$ & uN positive $n=11(69 \%)$ & \\
\hline \multirow[t]{4}{*}{ Pathological tumour stage $(n=32)$} & ypTONO $n=1$ & ypTONO $n=2$ & $p=0.69$ \\
\hline & ypT1-2N0 n = 6 & ypT1-2NO $n=6$ & \\
\hline & ypT3-4NO n = 6 & ypT3-4NO n = 2 & \\
\hline & ypTanyN+ n = 4 & ypTanyN+ $n=5$ & \\
\hline CEA (median) & 2.1 & 4.25 & $p=0.074$ \\
\hline CA 19-9 & 10 & 23 & $p=0.18$ \\
\hline VEGFR1 (median) & $0.4125 ; n=10$ & $0.1034 ; n=16$ & $p=0.19$ \\
\hline VEGFR2 (median) & $0.4413 ; n=16$ & $0.8241 ; n=16$ & $p=0.11$ \\
\hline Survivin $(\mathrm{n}=30)$ (median) & $6.4 ; n=17$ & $8.5 ; n=13$ & $p=0.081$ \\
\hline KRAS mutated $(n=14 / 33)$ & $\mathrm{n}=6(35 \%)$ & $n=8(50 \%)$ & $p=0.49$ \\
\hline Loss of PTEN $(n=2 / 30)$ & $n=1 / 16(6 \%)$ & $\mathrm{n}=1 / 14(7 \%)$ & $p=1.0$ \\
\hline Local recurrence & $\mathrm{n}=0(0 \%)$ & $n=2(12.5 \%)$ & $p=0.22$ \\
\hline Metastasis during follow up & $n=1(6 \%)$ & $n=9(56 \%)$ & $p=0.0024$ \\
\hline Median DFS $\infty$ (months) & 39 & 23 & $p=0.017$ \\
\hline Death & $\mathrm{n}=2(12 \%)$ & $n=4(25 \%)$ & $p=0.39$ \\
\hline Median Survival (months) & 39 & 26 & $p=0.26$ \\
\hline
\end{tabular}

$\infty$ disease-free survival

Shin and co-workers described an upregulation of glycolytic enzymes including Transketolase in 5-FU resistant colon cancer cell lines [34], an argument for the potential involvement of TKTL1 in progression and therapy resistance.

TKTL1 expression in colon cancer was shown to be upregulated as compared to TKT and TKTL2 expression using immunohistochemistry and cell culture assays $[14,17]$. Significant reduction in cell growth and viability in human LoVo and HCT116 colon cancer cells treated with TKTL1 siRNA as compared to LoVo/HCT116 cells without RNAi treatment in a cell culture model using quantitative PCR was demonstrated by two different groups [14,17]. Langbein et al. [16] examined untreated tumour tissue of 70 colon cancer patients and showed overexpression of TKTL1 in invasive carcinomas as compared to healthy tissue and non-invasive tumours on protein level. Overexpression of the TKTL1 protein was related to lower disease specific survival. In the same study, five colon cancer samples have been analysed by quantitative PCR, also showing TKTL1 overexpression in invasive carcinomas on mRNA level.

Although TKTL1 expression has been analysed in many solid tumours, to date no such analysis has been done for rectal cancer. Most of the studies focusing on TKTL1 expression in solid malignancies examined TKTL1 expression levels via immunohistochemistry, whereas expression on cDNA level has been examined less frequently.
Altered glucose consumption may also have therapeutic consequences: It became apparent that depletion of ATP by glycolytic inhibition potently induced apoptosis in multidrug-resistant cells in vitro [33,35]. Inhibition of the ultimate step in glycolysis (the conversion of pyruvate to lactate) has been proven to be effective in vivo and in vitro in breast cancer [36]. In addition, the activation of transketolases by application of thiamine stimulates tumour growth [37]. Specific inhibition of TKTL1 might be a useful target in this setting in cases, where TKTL1 expression is upregulated. To date, many preclinical glucose inhibitors have been developed, giving rise to a possibly new substance group in the near future [38].

In our analysis, TKTL1 expression significantly correlates with DFS and development of metastasis, whereas no significant difference for median survival, local recurrence rates or death could be found. The reason for this controversary again might be found in the sample size: all investigations show a trend towards better outcome in low TKTL1 expressing patients and should therefore be analyzed again in a larger cohort.

No correlation of TKTL1 expression with the other investigated markers could be detected in our study. Lack of prognostic value for survivin expression and KRAS/PTEN mutation status is in line with prior findings of our group $[28,29]$. A slight tendency towards higher survivin expression in patients overexpressing 
TKTL1 can be regarded as a possible response of tumour cells to hypoxic conditions. Survivin has been shown to being secreted as anti-apoptotic protein under hypoxic conditions [39].

In contrast to our findings concerning TKTL1, VEGFR-1/-2 expression does not seem to play a role as a predictive or prognostic marker in LARC in our cohort.

Importance of VEGF- as well as $V E G F$-subtype- and receptor-overexpression in solid tumours has been widely discussed in the last few years. VEGFR-1 is said to mediate biologic activity in human cancer cells [7], VEGFR-2 regulates downstream molecules such as PI3K or AKT and therewith steers endothelial differentiation, DNA synthesis and proliferation [40]. However, the actual impact of the receptors on therapeutic outcome and prognosis remains controversial. André et al. [9] found increased expression of VEGFR-1 and one of its ligands $V E G F-A$ on mRNA level in colon cancers, but could not outline a prognostic value. Bertolini and coworkers found no significant association between baseline expression of VEGF (measured by immunohistochemistry) and $\mathrm{pCR}$, disease free survival or overall survival analysing 91 patients with LARC. An increase in VEGF expression after the neoadjuvant treatment could be observed [41].

Another study analyzed VEGF expression using immunohistochemistry in 81 patients with LARC receiving neoadjuvant radiotherapy [5]. No significant correlation of $V E G F$-expression with the pCR and local relapse rate was observed while disease free survival was poor due to an increased rate of distant metastases.

In contrast, Zlobec et al. [8] analyzed 104 patients and found a significant correlation of VEGF levels with pCR rates using immunohistochemistry. Both studies may be criticized because pre-treatment was not standardized in the investigated patient population and differences between patients receiving radiotherapy only and those undergoing chemoradiation cannot be ruled out.

Our findings underline the involvement of VEGFR-1/2 in primary tumour growth and progression of rectal cancer due to significantly increased levels compared to normal tissue which is in line with the results reported by others [9]. VEGFR-1/-2 expression was not altered by the chemoradiotherapy regimen applied to the present patient group. VEGFR-1/2 expression did not correlate with tumour regression grade or tumour downsizing. Accordingly, no significant correlation between VEGFR1/-2 expression and DFS has been noted. However, a trend can be seen towards a better prognosis for patients with low VEGFR-2 expression (Figure 2). VEGFR-2 expression should therefore be analyzed with a larger number of patients. Several studies have analyzed gene expression by immunohistochemistry, while the present analysis has focused on mRNA expression of $V E G F$-receptors, which could explain the different results.

The lack of correlation between TKTL1 and VEGFR$1 / 2$ expression (Table 3 ) suggests that many different other mechanisms are involved in tumour growth and metastasis and that a change in tumour metabolism is only one of many alterations [42]. Again, it has to be mentioned that the sample size of the cohort was relatively low due to scantness of tumour tissue available, and investigation of a larger cohort size should be done in order to prove this hypothesis.

\section{Conclusion}

High TKTL1 expression strongly correlated with poor outcome in patients with LARC receiving neoadjuvant intensified chemoradiotherapy in the present analysis and may therefore be regarded as a potential prognostic marker. Further validation of TKTL1 in larger patient cohorts using multivariate analysis appears to be warranted. It also has to be proved, whether TKTL1 expression as a predictive marker can be used in patient groups with other treatment regimens apart from 5FU/ cetuximab/radiotherapy. Moreover, glucose metabolism as a "druggable" target in solid tumours is under current investigation and the potential links between high TKTL1 expression and the metastatic potential of tumours deserves further research. Expression of VEGFR-1/-2 did not correlate with disease-free survival in our study.

\section{Additional material}

Additional file 1: Primer sequences of VEGFR-1/-2 and TKTL1. Primer sequences of VEGFR-1/-2 and TKTL1 used in described PCR assays.

\section{Acknowledgement section}

The authors thank Maike Haas and Melanie Hartmann for excellent technical assistance.

\section{Author details}

${ }^{1}$ III. Medizinische Klinik, Universitätsmedizin Mannheim, Theodor-Kutzer-Ufer 1-3, 68167 Mannheim, Germany. ${ }^{2}$ Chirurgische Klinik, Universitätsmedizin Mannheim, Theodor-Kutzer-Ufer 1-3, 68167 Mannheim, Germany. ${ }^{3}$ Institut für Pathologie, Universitätsmedizin Mannheim, Theodor-Kutzer-Ufer 1-3, 68167 Mannheim, Germany. ${ }^{4}$ Klinik für Strahlentherapie und Radioonkologie, Universitätsmedizin Mannheim, Theodor-Kutzer-Ufer 1-3, 68167 Mannheim, Germany.

\section{Authors' contributions}

JS, KH, PE, PS, BB carried out the molecular genetic studies. JS, RDH and PE drafted the manuscript. RDH, PE, JS participated in the design of the study and performed the statistical analysis. Study material and/or patients were provided from DG; GK, PK, SP, WKH, FW and RDH. All authors read and approved the final manuscript.

\section{Competing interests}

The authors declare that they have no competing interests. 
Received: 22 March 2011 Accepted: 19 August 2011

Published: 19 August 2011

\section{References}

1. Sauer R, Becker H, Hohenberger W, Rodel C, Wittekind C, Fietkau R, Martus P, Tschmelitsch J, Hager E, Hess CF, et al: Preoperative versus postoperative chemoradiotherapy for rectal cancer. N Engl J Med 2004, 351(17):1731-1740.

2. Horisberger K, Erben P, Muessle B, Woernle C, Stroebel P, Kaehler G, Wenz F, Hochhaus A, Post S, Willeke F, et al: Topoisomerase I expression correlates to response to neoadjuvant irinotecan-based chemoradiation in rectal cancer. Anticancer Drugs 2009, 20(6):519-524.

3. Marquardt F, Rodel F, Capalbo G, Weiss C, Rodel C: Molecular targeted treatment and radiation therapy for rectal cancer. Strahlenther Onkol 2009, 185(6):371-378.

4. Folkman $\mathrm{J}$ : What is the evidence that tumors are angiogenesis dependent? I Natl Cancer Inst 1990, 82(1):4-6.

5. Giralt J, Navalpotro B, Hermosilla E, de Torres I, Espin E, Reyes V, Cerezo L, de las Heras M, Ramon y Cajal S, Armengol M, et al: Prognostic significance of vascular endothelial growth factor and cyclooxygenase-2 in patients with rectal cancer treated with preoperative radiotherapy. Oncology 2006, 71(5-6):312-319.

6. Tol J, Punt CJ: Monoclonal antibodies in the treatment of metastatic colorectal cancer: a review. Clin Ther 2010, 32(3):437-453.

7. Lesslie DP, Summy JM, Parikh NU, Fan F, Trevino JG, Sawyer TK, Metcalf CA, Shakespeare WC, Hicklin DJ, Ellis LM, et al: Vascular endothelial growth factor receptor-1 mediates migration of human colorectal carcinoma cells by activation of Src family kinases. Br J Cancer 2006, 94(11):1710-1717.

8. Zlobec I, Vuong T, Compton CC, Lugli A, Michel RP, Hayashi S, Jass JR: Combined analysis of VEGF and EGFR predicts complete tumour response in rectal cancer treated with preoperative radiotherapy. $\mathrm{Br} J$ Cancer 2008, 98(2):450-456.

9. Andre T, Kotelevets L, Vaillant JC, Coudray AM, Weber L, Prevot S, Parc R, Gespach C, Chastre E: Vegf, Vegf-B, Vegf-C and their receptors KDR, FLT-1 and FLT-4 during the neoplastic progression of human colonic mucosa. Int J Cancer 2000, 86(2):174-181.

10. Carlomagno C, Pepe S, D'Armiento FP, D'Armiento M, Cannella L, De Stefano A, Crispo A, Giordano M, De Placido S: Predictive factors of complete response to neoadjuvant chemoradiotherapy in patients with rectal cancer. Oncology 2010, 78(5-6):369-375.

11. Negri FV, Campanini N, Camisa R, Pucci F, Bui S, Ceccon G, Martinelli R, Fumagalli M, Losardo PL, Crafa P, et al: Biological predictive factors in rectal cancer treated with preoperative radiotherapy or radiochemotherapy. $\mathrm{Br} J$ Cancer 2008, 98(1):143-147.

12. Warburg O, Posener $K$, Negelein E: Ueber den Stoffwechsel der Carcinomzelle. Biochem Z 1924, 152:309-344.

13. Coy JF, Dressler D, Wilde J, Schubert P: Mutations in the transketolase-like gene TKTL1: clinical implications for neurodegenerative diseases, diabetes and cancer. Clin Lab 2005, 51(5-6):257-273.

14. Hu LH, Yang JH, Zhang DT, Zhang S, Wang L, Cai PC, Zheng JF, Huang JS: The TKTL1 gene influences total transketolase activity and cell proliferation in human colon cancer LoVo cells. Anticancer Drugs 2007, 18(4):427-433.

15. Langbein S, Frederiks WM, zur Hausen A, Popa J, Lehmann J, Weiss C Alken P, Coy JF: Metastasis is promoted by a bioenergetic switch: new targets for progressive renal cell cancer. Int J Cancer 2008, 122(11):2422-2428.

16. Langbein S, Zerilli M, Zur Hausen A, Staiger W, Rensch-Boschert K, Lukan N, Popa J, Ternullo MP, Steidler A, Weiss C, et al: Expression of transketolase TKTL1 predicts colon and urothelial cancer patient survival: Warburg effect reinterpreted. Br J Cancer 2006, 94(4):578-585.

17. Xu X, Zur Hausen A, Coy JF, Lochelt M: Transketolase-like protein 1 (TKTL1) is required for rapid cell growth and full viability of human tumor cells. Int I Cancer 2009, 124(6):1330-1337.

18. Zhang S, Yue JX, Yang JH, Cai PC, Kong WJ: Overexpression of transketolase protein TKTL1 is associated with occurrence and progression in nasopharyngeal carcinoma: a potential therapeutic target in nasopharyngeal carcinoma. Cancer Biol Ther 2008, 7(4):517-522.

19. Hofheinz RD, Horisberger K, Woernle C, Wenz F, Kraus-Tiefenbacher U, Kahler G, Dinter D, Grobholz R, Heeger S, Post S, et al: Phase I trial of cetuximab in combination with capecitabine, weekly irinotecan, and radiotherapy as neoadjuvant therapy for rectal cancer. Int I Radiat Oncol Biol Phys 2006, 66(5):1384-1390.

20. Horisberger K, Treschl A, Mai S, Barreto-Miranda M, Kienle P, Strobel P, Erben P, Woernle C, Dinter D, Kahler G, et al: Cetuximab in combination with capecitabine, irinotecan, and radiotherapy for patients with locally advanced rectal cancer: results of a Phase II MARGIT trial. Int I Radiat Oncol Biol Phys 2009, 74(5):1487-1493.

21. Schmiegel W, Adler G, Fruhmorgen P, Folsch U, Graeven U, Layer P, Petrasch S, Porschen R, Pox C, Sauerbruch T, et al: Colorectal carcinoma: prevention and early detection in an asymptomatic populationprevention in patients at risk-endoscopic diagnosis, therapy and aftercare of polyps and carcinomas. German Society of Digestive and Metabolic Diseases/Study Group for Gastrointestinal Oncology. Z Gastroenterol 2000, 38(1):49-75.

22. Compton CC: Updated protocol for the examination of specimens from patients with carcinomas of the colon and rectum, excluding carcinoid tumors, lymphomas, sarcomas, and tumors of the vermiform appendix: a basis for checklists. Cancer Committee. Arch Pathol Lab Med 2000, 124(7):1016-1025.

23. (JSCCR) JSfCotCaR: Japanese classification of colorectal carcinoma, 1st English ed. 1997.

24. Valentini V, Coco C, Picciocchi A, Morganti AG, Trodella L, Ciabattoni A, Cellini F, Barbaro B, Cogliandolo S, Nuzzo G, et al: Does downstaging predict improved outcome after preoperative chemoradiation for extraperitoneal locally advanced rectal cancer? A long-term analysis of 165 patients. Int I Radiat Oncol Biol Phys 2002, 53(3):664-674

25. Erben P, Horisberger K, Muessle B, Muller MC, Treschl A, Ernst T, Kahler G, Strobel $\mathrm{P}$, Wenz F, Kienle $\mathrm{P}$, et al: mRNA expression of platelet-derived growth factor receptor-beta and C-KIT: correlation with pathologic response to cetuximab-based chemoradiotherapy in patients with rectal cancer. Int J Radiat Oncol Biol Phys 2008, 72(5):1544-1550.

26. van der Velden VH, Hochhaus A, Cazzaniga G, Szczepanski T, Gabert J, van Dongen JJ: Detection of minimal residual disease in hematologic malignancies by real-time quantitative PCR: principles, approaches, and laboratory aspects. Leukemia 2003, 17(6):1013-1034.

27. Muller MC, Erben P, Saglio G, Gottardi E, Nyvold CG, Schenk T, Ernst T, Lauber S, Kruth J, Hehlmann R, et al: Harmonization of BCR-ABL mRNA quantification using a uniform multifunctional control plasmid in 37 international laboratories. Leukemia 2008, 22(1):96-102.

28. Erben P, Strobel P, Horisberger K, Popa J, Bohn B, Hanfstein B, Kahler G, Kienle P, Post S, Wenz F, et al: KRAS and BRAF Mutations and PTEN Expression Do Not Predict Efficacy of Cetuximab-Based Chemoradiotherapy in Locally Advanced Rectal Cancer. Int I Radiat Oncol Biol Phys 2010.

29. Horisberger K, Erben P, Strobel P, Bohn B, Hahn M, Kahler G, Wenz F, Hochhaus A, Post S, Willeke F, et al: Annexin and survivin in locally advanced rectal cancer: indicators of resistance to preoperative chemoradiotherapy? Onkologie 2010, 33(8-9):439-444.

30. Postovit LM, Adams MA, Lash GE, Heaton JP, Graham CH: Oxygenmediated regulation of tumor cell invasiveness. Involvement of a nitric oxide signaling pathway. J Biol Chem 2002, 277(38):35730-35737.

31. Younes $M$, Lechago LV, Lechago J: Overexpression of the human erythrocyte glucose transporter occurs as a late event in human colorectal carcinogenesis and is associated with an increased incidence of lymph node metastases. Clin Cancer Res 1996, 2(7):1151-1154.

32. Staiger WI, Coy JF, Grobholz R, Hofheinz RD, Lukan N, Post S, Schwarzbach MH, Willeke F: Expression of the mutated transketolase TKTL1, a molecular marker in gastric cancer. Oncol Rep 2006, 16(4):657-661.

33. Boros LG, Puigjaner J, Cascante M, Lee WN, Brandes JL, Bassilian S, Yusuf FI, Williams RD, Muscarella P, Melvin WS, et al: Oxythiamine and dehydroepiandrosterone inhibit the nonoxidative synthesis of ribose and tumor cell proliferation. Cancer Res 1997, 57(19):4242-4248.

34. Shin YK, Yoo BC, Hong YS, Chang HJ, Jung KH, Jeong SY, Park JG: Upregulation of glycolytic enzymes in proteins secreted from human colon cancer cells with 5-fluorouracil resistance. Electrophoresis 2009, 30(12):2182-2192.

35. Xu RH, Pelicano H, Zhou Y, Carew JS, Feng L, Bhalla KN, Keating MJ, Huang P: Inhibition of glycolysis in cancer cells: a novel strategy to overcome drug resistance associated with mitochondrial respiratory defect and hypoxia. Cancer Res 2005, 65(2):613-621. 
36. Fantin VR, St-Pierre J, Leder P: Attenuation of LDH-A expression uncovers a link between glycolysis, mitochondrial physiology, and tumor maintenance. Cancer Cell 2006, 9(6):425-434.

37. Comin-Anduix B, Boren J, Martinez S, Moro C, Centelles JJ, Trebukhina R, Petushok N, Lee WN, Boros LG, Cascante M: The effect of thiamine supplementation on tumour proliferation. A metabolic control analysis study. Eur J Biochem 2001, 268(15):4177-4182.

38. Mathupala SP, Colen CB, Parajuli P, Sloan AE: Lactate and malignant tumors: a therapeutic target at the end stage of glycolysis. J Bioenerg Biomembr 2007, 39(1):73-77.

39. Chacko SM, Ahmed S, Selvendiran K, Kuppusamy ML, Khan M, Kuppusamy P: Hypoxic preconditioning induces the expression of prosurvival and pro-angiogenic markers in mesenchymal stem cells. Am J Physiol Cell Physiol 2010.

40. Waltenberger J, Claesson-Welsh L, Siegbahn A, Shibuya M, Heldin CH: Different signal transduction properties of KDR and Flt1, two receptors for vascular endothelial growth factor. J Biol Chem 1994, 269(43):26988-26995.

41. Bertolini F, Bengala C, Losi L, Pagano M, lachetta F, Dealis C, Jovic G, Depenni R, Zironi S, Falchi AM, et al: Prognostic and predictive value of baseline and posttreatment molecular marker expression in locally advanced rectal cancer treated with neoadjuvant chemoradiotherapy. Int J Radiat Oncol Biol Phys 2007, 68(5):1455-1461.

42. Luo J, Solimini NL, Elledge SJ: Principles of cancer therapy: oncogene and non-oncogene addiction. Cell 2009, 136(5):823-837.

\section{Pre-publication history}

The pre-publication history for this paper can be accessed here: http://www.biomedcentral.com/1471-2407/11/363/prepub

doi:10.1186/1471-2407-11-363

Cite this article as: Schwaab et al.: Expression of Transketolase like gene 1 (TKTL1) predicts disease-free survival in patients with locally advanced rectal cancer receiving neoadjuvant chemoradiotherapy. BMC Cancer 2011 11:363.

\section{Submit your next manuscript to BioMed Central and take full advantage of:}

- Convenient online submission

- Thorough peer review

- No space constraints or color figure charges

- Immediate publication on acceptance

- Inclusion in PubMed, CAS, Scopus and Google Scholar

- Research which is freely available for redistribution

Submit your manuscript at www.biomedcentral.com/submit 